\title{
Globalização financeira e associações de bancos no B rasil: o caso da Febraban
}

\author{
ElfLay Miranda*
}

\begin{abstract}
R esumo: O presente artigo faz uma análise, mediante uma visão socigpolítica, da estnutura e da dinâmica de funcionamento de um dos mais importantes órgãos de representação de classe do empresariado financeiro brasileiro: a Federação Brasileira das Associaçães de Bancos (Febraban), no período compreendido entre as duas gestões 1998 a 2001 e no períodb 2001 a 2003. Foram analisados a composição da diretoria e os vínculos dos diretores da entidade com outras organizaçães, como também algumas de suas disposiçães sobre temas que figuraram no cenário político-econâmico brasileiro, como as disposiçães scbre o artigo 192 da Constituição que trata do sistema financeiro nacional.
\end{abstract}

Palavras-chave: empresariado financeiro; Febraban; bancos; sistema financeiro.

0 atual processo de globalização financeira e suas transformações a partir da última década e início desta incluíram, entre outros aspectos, maior desregulamentação e abertura dos sistemas financeiros nacionais à participação de instituições financeiras estrangeiras, juntamente com as modificações nos sistemas político-el eitorais.

0 B rasil, pelo menos nos últimos anos, favoreceu esse processo de globalização com a crescente abertura da economia. A briu mercados, privatizou empresas estatais, aumentou taxas de juros e impostos, cortou gastos públicos, fez mudanças na previdência social, favoreceu bancos privados e introduziu programas como Proer, ${ }^{1}$ sempre auxiliado por vultuosos apoios financeiros de organismos internacionais. Contudo, o país carrega grandes passivos sociais e não consegue mais do que soluços nas suas tentativas de crescimento.

\footnotetext{
** M estrando do Programa de Pós-Graduação em Sociologia Política da UFSC. E-mail: elflay_miranda@ hotmail.com.

1. Proer - Programa de Estímulo à Reestruturação e ao Sistema Financeiro Nacional - criado em 4 de novembro de 1995, sob Medida Provisória (M P), com o objetivo de assegurar a liquidez e solvência ao sistema financeiro nacional e resguardar os interesses dos depositantes e dos investidores.
}

Essas transformações parecem corresponder a uma fase contemporânea do capitalismo, que na literatura atual apresenta-se com várias denominações: "financeirização da riqueza" (B raga, 1997), "novo regime de acumulação sob dominância financeira" (Chesnais, 1997) ou "tirania financeira" (Fitoussi, 1997), dentre outras. Esse novo modelo de internacionalização dos sistemas financeiros obedece a uma nova lógica do capitalismo em que

a mundialização do capital deve ser entendida como mais do que uma fase suplementar no processo de internacional ização do capital iniciado há mais de um século, ou até mesmo como qual quer outra coisa. (Chesnais, 1997, p. 19)

Especialmente na A mérica Latina, essas modificações tiveram enormes impactos sobre a estrutura e a dinâmica de representação de classe do empresariado financeiro, em que podemos considerar aspectos relevantes como o grau de abertura financeira que os governos latino-americanos proporcionaram, em ritmos diferentes, resultando no aumento do número 
de instituições estrangeiras e no volume de ativos controlados por tais instituições.

Essas instituições assumiram um importante papel no processo de privatização de empresas públicas brasileiras, principalmente de bancos estatais, mediante a participação acionária ou entrega de seu controle a um novo grupo econômico/financeiro.

O s grupos financeiros são entendidos aqui, de forma mais genérica, como um conjunto de empresas interligadas entre si e que incluem a participação de uma ou mais instituições financeiras.

0 poder econômico-político que o empresariado financeiro adquiriu nas úl timas décadas, juntamente com seus órgãos de representação de classe, deu-Ihe bases para intervir nas tomadas de decisão do aparato estatal por meio de grupos de pressão, seja no Poder Executivo, seja no Poder L egislativo. Vale dizer,

os grandes grupos empresariais dos setores industrial e financeiro, como é sabido, sempre se beneficiaram de um acesso privilegiado às altas instâncias do Executivo, tanto através de vínculos pessoais como por via da estrutura corporativa. (Boschi, Diniz eSantos, 2000, p. 77)

E m interessante estudo comparativo sobre as organizações de representação de classe do setor financeiro nos países capital istas da E uropa e da A mérica do N orte, Coleman (1994) analisou a questão do poder político e o sistema de intermediação de interesses a partir de um conjunto de indicadores empíricos das situações organizacionais das associações do empresariado financeiro. Com particular interesse nesse estudo, podemos estabelecer uma relação entre o sistema de representação de classe e 0 processo de globalização financeira ocorrido tanto em países por ele pesquisados como também na $A$ mérica $L$ atina, mais precisamente no $B$ rasil (M inella, 2001).

A questão central que colocamos diz respeito à relação entre o processo de globalização financeira e a estrutura dinâmica dos órgãos de representação de classe do empresariado financeiro - especialmente as associações de bancos na A mérica Latina -, em que se torna oportuno analisar a existência dos grupos financeiros e o controle sobre o fluxo de capitais, como também a participação no processo político e nos aparatos de decisão do Estado.

\section{O sistema financeiro brasileiro}

0 processo de abertura financeira no B rasil, nos últimos anos, fez com o país modificasse a estrutura e a dinâmica de funcionamento de seu sistema financeiro a fim de se adequar às novas tendências da economia mundial.

As condições para o desenvolvimento de um sistema financeiro envolvem aspectos estruturais como a natureza dos mercados e seu relacionamento com as mais variadas instituições, tanto político-econômicas e financeiras como também com todo 0 aparato legal que dá respaldo ao funcionamento dessas instituições. Envolvem, ainda, aspectos operacionais relativos aos tipos de papéis utilizados nas transações financeiras e as macropolíticas monetárias utilizadas na dinâmica de seu funcionamento. $\mathrm{N}$ ão podemos esquecer ainda as modificações que ocorreram no valor e na qualidade dos serviços oferecidos pelas instituições financeiras, os métodos de captação de recursos e de concessão de créditos. Vale assinalar, todos esses aspectos reunidos ditam a nova estrutura do sistema financeiro nacional, que parece ainda estar se adequando aos novos padrões internacionais de funcionamento.

A estrutura de um sistema financeiro sólido depende de que se consiga responder a várias questões, dentre elas a forma mais apropriada para o seu funcionamento, tendo em vista 0 crescimento econômico do país, visando assegurar um model o econômico claro e compatível com os anseios da população. A ssim, as autoridades que respondem pelas políticas econômicas do sistema financeiro nacional precisam achar respostas plausíveis a desafios como a estabilização econômica, o crescimento interno, o combate à inflação, a estabilização monetária, como também o combate à pobreza e às injustiças sociais.

Devemos lembrar que a configuração do Sistema Financeiro N acional (SF N) desenhado a partir de 1964, no Governo Castelo Branco, sofreu mudanças a partir da Constituição de 1988, em que a instância superior e reguladora 
do SFN passou a ser o Conselho Monetário Nacional (CMN), sendo o Banco Central do $B$ rasil ( $B$ acen) e o $C M N$ as principais agências governamentais de decisão político-econômica.

O CM N, por meio da Resolução nº 1524, de 21 de setembro de 1988, introduziu uma reforma importante no sistema financeiro com a criação dos bancos múltiplos. Trata-se de resolução que permitiu que os bancos comerciais, de investimentos ou desenvolvimento, as sociedades de crédito, financiamento e investimento e as sociedades de crédito imobiliário se organizassem como uma única instituição financeira: o banco múltiplo.

O utra importante reforma introduzida pelo CMN foi por meio da Resolução $n^{0} 2.099$, de 17 de agosto de 1994, que regulamentou as normas que implementaram o A cordo de Basiléia, ${ }^{2}$ enquadrando o sistema financeiro brasileiro dentro dos padrões internacionais de funcionamento. Segundo dados do B acen, ${ }^{3}$ após essa resolução, um banco múltiplo, por exemplo, para entrar em operação, deve ter pelo menos um capital mínimo de $\mathrm{R} \$ 10$ milhões, se optar por uma cartei ra comercial, ou de R $\$ 9$ milhões, se preferir por uma carteira de investimento.

A Constituição de 1988 estabeleceu no seu artigo 192 que a autorização para funcionamento de uma instituição financeira seria inegociável e intransferível, permitindo, todavia, a transmissão de controle de pessoa jurídica. Esse dispositivo constitucional acabou com a carta-patente, removendo, então, a barreira para entrada de novas instituições SFN. A carta-patente era a concessão dada pelo B anco Central para o funcionamento de uma instituição financeira. Como a concessão de novas autorizações era limitada, a possibilidade de obter uma cartapatente passou a ser um dos maiores atrativos para os bancos que compraram instituições fal idas ou em dificuldades nas décadas de 1970 e 1980.

2. O A cordo de Basiléia estabeleceu o limite mínimo de capital para a constituição de um banco e limites adicionais de acordo com o grau de risco da estrutura dos ativos bancários. Essa exigência de capital mínimo, tal como definido pelo Comitê da Basiléia, tem o objetivo de servir de funding permanente para as atividades do banco e de ser uma reserva contra o risco e as perdas decorrentes das operações bancárias.

3. www.bc.gov.br, acessado em 25 fev. 2003.
A partir de 1988, ocorreu uma expansão do sistema bancário brasileiro, impulsionado principal mente pela eliminação da carta-patente, o que fez com que o número de bancos quase dobrasse, passando de um total de 103 bancos em 1988 para 194 instituições no final de 2002.

A té 1994 a economia brasileira possuía como uma das suas principais características um acentuado processo inflacionário. Com a aparente redução dos níveis de inflação proporcionados pelo Plano R eal e a mai or abertura da economia, as instituições de menor porte não conseguiram se ajustar às condicionantes macroeconômicas exigidas pelo Plano. Diante dessa nova dinâmica, os bancos que continuaram a fazer parte do SFN tiveram de encontrar soluções para enfrentar os problemas no mercado financeiro da época. A alternativa adotada por algumas instituições foi a de transferir 0 controle acionário para outras de maior porte, até mesmo com a participação de capital estrangeiro nas operações de compra e venda de seus ativos, juntamente com fusões ou incorporações, diminuindo substancialmente 0 número de bancos.

0 acentuado processo de privatização de bancos públicos ocorridos em paralelo ao Plano Real também colaborou com a diminuição do número de bancos. Segundo Relatório do B acen, ${ }^{4}$ do grupo de bancos que funcionava em dezembro de 1988, cerca de $40 \%$ não chegaram a 2000 e quase metade deles saiu do SFN por motivo de liquidação. Esses bancos se retiraram do sistema bancário após um tempo médio de 48 anos de atividades.

Para o B acen, ${ }^{5}$ as elevadas taxas de inflação, que em outras experiências históricas levaram economias à desmonetarização, no B rasil contribuíram para alavancar a participação do setor financeiro na renda nacional. 0 fato de os bancos implementarem inovações financeiras, aproveitando-se das oportunidades regulatórias, permitiu tanto um acúmulo de

\footnotetext{
4. Relatório da Evolução do Sistema Financeiro Nacional: B ancos Brasileiros de dez. 1988 a dez. 2000. Disponível em: <www.bc.gov.br/htms/deorf/e88-2000.htm> A cesso em: 30 jan. 2003.

5. Relatório da Evolução do Sistema Financeiro Nacional: Bancos Brasileiros de dez. 1988 a dez. 2000. Disponível em: <www.bc.gov.br/htms/deorf/e88-2000.htm> A cesso em: 30 jan. 2003
} 
capital quanto um desenvolvimento tecnológico. Durante o período inflacionário, a atividade financeira nos bancos sustentava-se dos recursos em trânsito (floating) e do financiamento do desequilíbrio das contas públicas, concentrando-se em operações de curto prazo.

Os bancos no governo do presidente Fernando Henrique Cardoso ( $F H C$ ) tiveram ainda bons desempenhos com ganhos obtidos nas operações de juros e câmbio e operações com títulos evalores mobiliários. Outro fator que explica 0 acúmulo de capital adquirido pelos bancos a partir de 1994 são as operações com altos spreads (diferença entre o custo de captação de recursos e a taxa de juros cobrada pel os tomadores de crédito).

\section{A bertura ao capital estrangeiro}

A partir da segunda metade da década de 1980, observa-se, nas economias latinoamericanas, uma intensificação do investimento estrangeiro nos mercados financeiros nacionais. Esse processo de internacionalização, inserido em um movimento mais geral das transformações do mercado financeiro internacional, não é homogêneo em todos os países, pois depende de dois fatores importantes: do grau de abertura financeira e da gestão macroeconômica adotada sobre os fluxos de capitais nesses países (F reitas e Prates, 1998).

A abertura da economia ao mercado internacional, como um dos principais condicionantes do processo de globalização financeira implementado pela reformas neoliberais nos últimos anos, fez com que países como o B rasil direcionassem sua política econômica rumo à adoção dos princípios discutidos no Consenso de Washington ${ }^{6}$ (R ocha, 2002). A ssim,

as reformas neoliberais e a estabilização inflacionária, a exemplo de países latinoamericanos como A rgentina, Chile e M éxico,

6. Expressão utilizada para se referir ao mínimo denominador comum das opiniões dos organismos internacionais e dos países membros para as reformas econômicas na A mérica Latina em 1989. Essas reformas incluíam disciplina fiscal, redirecionamento do gasto público, reforma tributária, liberalização das taxas de juros, taxa de câmbio competitiva, liberalização comercial e dos fluxos de investimentos estrangeiros diretos, privatizações, desregulamentação e garantia dos direitos de propriedade. passam a ser condições indispensáveis para a nova inclusão do Brasil na rota dos investimentos externos. (Rocha, 2002, p. 73)

No B rasil, a abertura financeira sofrida na década de 1990 liberalizou significamente os investimentos estrangeiros no mercado financeiro deste país. Contudo, esse movimento foi menos intenso que na A rgentina e no M éxico, que liberaram de formas diferenciadas seus mercados monetários, de renda fixa e acionário (Freitas e Prates, 1998).

A Constituição de 1988 tornou mais difícil 0 acesso do capital internacional ao SFN. Isso porque a regulamentação da entrada do capital estava vinculada à aprovação do artigo 192, que trata do funcionamento do SFN. Todavia, 0 artigo 52, que trata das Disposições Constitucionais Transitórias, em seus incisos I e II, deixou em aberto a possibilidade da entrada de instituições financeiras estrangeiras no SFN brasileiro, pelas autorizações resultantes dos acordos internacionais e pela aplicação do princípio de reciprocidade, ou seja, a abertura de filiais de bancos estrangeiros no exterior (Freitas e Prates, 1998).

U ma das mais importantes medidas de abertura financeira no Brasil foi a Resolução do $C M N n^{0} 1.832$, de 31 de maio de 1991, que instituiu o A nexo IV à R esolução 1.289, de 20 de março de 1987, que permite e regulamenta os investimentos estrangeiros em títulos e valores mobiliários nas companhias abertas brasileiras. Esse foi um dos mecanismos mais utilizados para a entrada de recursos externos no mercado financeiro brasileiro (Rocha, 2002). Segundo Freitas e Prates (1998, p. 183), "no $B$ rasil, quase a totalidade dos investimentos estrangeiros de porto-fólio direcionaram-se para a Bolsa de Valores do Estado de São Paulo (Bovespa), a maior bolsa de valores do país".

A abertura do mercado de capitais, o processo de privatização e os negócios associados ao financiamento da renovação da infraestrutura econômica foram os principais atrativos para o investimento estrangei ro direto no sistema financeiro brasileiro (Freitas e Prates, 1998).

Segundo o B acen, ${ }^{7}$ considerando-se apenas os casos individualmente mais expressivos, os

7. BRASIL. Mensagem ao Congresso Nacional: abertura da 4a Sessão Legislativa Ordinária da 51a L egislatura/Fernando Henrique Cardoso. Brasília: Presidência da República, Se 
investimentos estrangeiros e a capitalização de instituições financeiras preexistentes superaram $\mathrm{R} \$ 20$ bilhões em 2002.

0 processo mais intenso de entrada de capital internacional no SFN ocorreu a partir de 1998, ano da reeleição de FHC. De um total de $7,16 \%$ em 1994, início do Plano Real, os bancos estrangeiros fecham o ano de 2001 com 29,86\% do controle de ativos do sistema bancário brasileiro. Em um levantamento feito pela Consultoria $A B M$, os bancos internacionais tiveram, para cada $R \$ 100$ investidos no país, um retorno entre $R \$ 22$ e $R \$ 56.8$

Outro fator que explica os ganhos dos bancos estrangeiros no país foi a desval orização do R eal, que chegou a $61,6 \%$ em 2002. Ganhos com as compras de títul os públicos, remunerados por juros al tos e maiores receitas com serviços bancários, também contribuíram para rentabilidade dos bancos estrangeiros. Por meio desses indicadores, podemos concluir que a combinação entre câmbio desvalorizado ejuros altos faz com que os bancos estrangei ros sejam bem rentáveis no B rasil. Segundo a Consultoria $A B M$, os bancos estrangeiros que operam no $B$ rasil precisam de menos capital investido para ter retornos al tos porque ganham emprestando a taxas de juros muito al tas. ${ }^{9}$

\section{O poder dos bancos no cenário do Sistema} Financeiro Brasileiro

0 empresariado financeiro no Brasil se caracteriza pela adoção dos mais variados mecanismos de ação política. A lém das formas de atuação política institucionalizada - sob a forma de organizações ou de representação no Executivo e no Legislativo -, grandes empresários têm a possibilidade de ação direta, já que representam por si só um volume de capital significativo (M ick,1998).

A ssim, é preciso identificar a organização e predisposição do empresariado para o confronto político e as linhas de motivação para a ação, seja por suas características explícitas (bases produtivas, organizacional, geográfica e

cretaria de Comunicação de Governo, 2002, p. 300 (Documentos da Presidência da República). Disponível em: <www.presidencia.gov.br> A cesso em: 25 fev. 2003.

8. Folha de São Paulo, 15 dez. 2002, p. B1.

9. Idem. social; manifestações políticas e ideológicas) ou pelas características e traços intrínsecos, inerentes, esperados e latentes (cognição social, normas e valores dominantes) (D reifuss, 1986).

Segundo Boschi, Diniz \& Santos (2000, p. 77)

os grandes grupos empresariais dos setores industrial efinanceiro, como é sabido, sempre se beneficiaram de um acesso privilegiado às altas instâncias do Executivo, tanto através de vínculos pessoais como por via da estrutura corporativa.

Em 1994, segundo dados do Tribunal Superior Eleitoral (TSE), os bancos foram os maiores contribuintes para a campanha presidencial de FHC. Também em 1998, os bancos e outras insti tuições financei ras foram os principais doadores de recursos para sua reeleição. $N$ as eleições de 1998, o maior doador para campanha FHC foi o Grupo Itaú e o terceiro maior doador também era do setor financeiro; o Real $A B N$ A M RO Bank. ${ }^{10}$

Um estudo feito pela Consultoria A ustin A sis, uma das maiores consultorias do país especial izadas em análise de bal anços de instituições financeiras, mostra que os bancos acumularam no governo $F H C$ pouco mais de $R \$ 21$ bilhões em lucros, até2001. A consul toria mostra também que o lucro dos 30 maiores bancos cresceu 313\% de dezembro de 1994 até dezembro de $2001,{ }^{11}$ e ainda que os bancos tiveram uma rentabilidade recorde em 2002. Em seu levantamento, os bancos lucram em média $24,5 \%$ com um ganho total de $R \$ 9,8$ bilhões. Vale destacar, o maior lucro registrado foi o do Banes$\mathrm{pa}$ ( $R \$ 2,8$ bilhões), sendo que os bancos tiveram uma rentabilidade média de 19,9\% sobre seu patrimônio líquido, no período do Plano R eal. ${ }^{12}$

$\mathrm{Na}$ úl tima campanha presidencial, 0 candidato Ciro Gomes (PPS) admitiu aceitar doações de banqueiros. "A s doações de banqueiros serão bem-vindas, desde que sejam feitas dentro da lei e sob o manto das nossas propostas", disse 0 coordenador político da campanha, deputado J oão Hermann N eto. ${ }^{13}$

\footnotetext{
10. Folha de São Paulo, 26 nov. 1998, p. 1-4.

11. Jornal do Brasil, 21 nov. 2001.

12. Folha de São Paulo, 16 fev. 2003, p. B1.

13. Agência Estado, 23 jul. 2002.
} 
0 candidato à presidência da R epública L uiz Inácio Lula da Silva também recebeu apoio de firmas comerciais, bancos e instuições financeiras para sua campanha el eitoral. Entre outras instuições, pode ser citada a BM G L easing, que também contribuiu com o partido. $O \mathrm{~B}$ anespa Santander aparece em segundo lugar na relação de pessoas jurídicas que abasteceram o comitê petista nessa última campanha eleitoral, e o $B$ anco $A$ Ifa I nvestimentos também figura na lista de doadores para campanha. ${ }^{14}$

Concluindo, podemos considerar o financiamento de campanhas eleitorais como um indicador da estreita relação entre o empresariado financeiro e o E stado. Vale dizer, participando e financiando o processo político, o empresariado financeiro tem mais acesso na definição de políticas e defesa de seus interesses.

\section{As federações de bancos: Febraban e Fenaban}

A Febraban foi fundada em 1967, por iniciativa das associações de bancos de alguns estados, interessadas em convergir seus interesses em relação ao sistema financeiro nacional. É uma entidade de natureza civil, associativa, com sede em São Paulo (capital), cuja presidência sempre foi ocupada por grandes bancos do cenário financeiro brasileiro, como 0 B anco B amerindus, no período de 1994 a 1997, - Itaú, de 1997 a 2001, o U nibanco, no último triênio 2001-2004. A tual mente, a presidência da entidade é ocupada pelo Bradesco e vai até março de 2007. A ssinalemos, esses bancos figuraram nos últimos anos entre os dez maiores bancos do país no ranking das instituições financeiras. ${ }^{15}$

Em junho de 2000, 128 bancos estavam associados à Febraban e, em fevereiro de 2002, o número de associados passou a ser de 117 bancos (privados, públicos, comerciais e múltiplos), representando mais de $90 \%$ das operações ativas no setor. ${ }^{16}$

14. Agência Estado, 11 ago. 2002.

15. Fonte: Revista Exame: Melhores e Maiores - as 500 maiores empresas do Brasil, anos 1997 a 2002.

16. Fonte: <www.febraban.org.br> A cesso em: 20 fev. 2004.
Os bancos possuem ainda uma entidade de caráter sindical, a Federação Nacional dos $B$ ancos (Fenaban), principal interlocutora dos bancos com as entidades representativas (sindicatos) dos bancários. A entidade conta com Comissões Consultivas de R elações TrabaIhistas e Sindicais (CCRTS) e uma Comissão de Negociações (CN), que têm o papel de negociar com os sindicatos dos trabalhadores as convenções coletivas de trabalho bancário.

No que se refere ao trabalho bancário, houve uma reorganização de seu perfil operacional, impulsionado pelas transformações do sistema financeiro nos últimos anos. Segundo Jinkings (2002, p. 80),

tal movimento vai consolidando o modelo de sistema bancário concebido pela Fenaban, caracterizado por densa concentração de capital privado, altamente informatizado, empregando força de trabalho mais escolarizada, tendo como epicentro da atividade 0 negócio e a venda de produtos e serviços a clientes discriminados e selecionados segundo critérios de renda ou patrimônio financeiro. ${ }^{17}$

A Febraban dispõe de comissões técnicas e mantém uma estrutura de apoio com assessores especial izados nas diversas áreas de atuação do sistema financeiro com consultoria jurídica, administrativo-financeira, tecnológica, relações de trabalho, economia, comunicação social e operacional. A lém disso, ela se apóia em discussões sobre a legislação que disciplina as atividades do setor financeiro no país. As assessorias técnicas são vinculadas à direção geral da Febraban, que atualmente é presidida pelo representante do $B$ anco do Brasil na entidade.

Convém destacar que estudar a estrutura, a dinâmica e a composição da diretoria das A ssociações de classe do empresariado financeiro como a F ebraban nos ajuda a compreender, em um universo mais amplo, as relações e os canais criados por esse segmento do empresariado com os demais órgãos associativos do meio empresarial, industrial, financeiro e político do país, incluindo aí o Estado.

16. Fonte: <www.febraban.org.br> A cesso em: 20 fev. 2004. 17. Em relação ao trabalho bancário, ver Minella (1988) e jinkings (1995 e 2002). 
Febraban: gestão 1998-2001

A análise desta gestão da Febraban se justifica pelo fato de o período correspondido entre 1998-2001 ser de um cenário marcado por várias transformações não só no âmbito do sistema financeiro, ocasionado pela ampliação no volume de capitais internacionais, mas também nas empresas brasilei ras produtoras de bens de consumo duráveis e não-duráveis, que foram alvos de aquisições por multinacionais e empresas estrangeiras.

Com uma política monetária restritiva adotada diante dos impactos da crise asiática, bem como das exigências de capital ização por parte do $B$ acen, um novo contingente de instituições financeiras estava a ponto de venda. 0 episódio de internacional ização bancária que vinha ocorrendo ressaltou as limitações do sistema financeiro doméstico, para evitar a desnacionalização bancária, em que o setor público era avalista e financiador desse processo (Rocha, 2002).

A internacionalização do sistema financeiro é constante na pauta de discussões da entidade, pois no discurso de encerramento dessa gestão, o então presidente e diretor do Banco Itaú, Roberto Egydio Setúbal, afirmou:

assim, hoje é expressiva a representação de bancos estrangeiros, além dos federais e privados nacionais na diretoria. Creio ser fundamental esse bom entendimento entre os principais participantes do mercando bancário no sentido de dar respostas uniformes às questões levantadas com relação ao papel dos bancos em nossa sociedade. ${ }^{18}$

No Q uadro 1, podemos observar os vínculos dos diretores da Febraban, no período de 1998-2001, com as mais variadas organizações, sejam privadas nacionais, internacionais ou estatais. Podemos observar, ainda, que os bancos estrangeiros ocupam 33\% da diretoria, sendo um forte indicador da representação do capital internacional, principalmente europeu, na diretoria da entidade. 0 banco europeu HSBC apresenta uma forte representatividade, ao

18. Discurso do presidente Roberto Egydio Setúbal na solenidade de encerramento da gestão da diretoria Febraban/ Fenaban 1998-2001, realizado em 12 de março de 2001 no Clube Monte Líbano em São Paulo. ocupar duas diretorias, uma di retamente e outra através do $B$ anco CCF B rasil, que é seu subsidiário. Outro fator a ser considerado é que $58,33 \%$ da diretoria é formada pelos dez maiores bancos do sistema financeiro no período. ${ }^{19}$ Três diretores da ainda Febraban são ligados à Câmara A mericana de Comércio (A M C HA M ), uma atuante entidade empresarial no comércio entre o B rasil e os Estados U nidos.

Febraban: gestão 2001-2004

A diretoria da Febraban neste período, ainda em curso (o mandato dos diretores encerra em março de 2004), tem como principal acontecimento as el eições para Câmara Federal, A ssembléias L egislativas, governos estaduaise presidência da República.

0 presidente da Febraban, na época da pesquisa, era 0 advogado Gabriel J orge Ferreira. Desde 1958, é funcionário de carreira e atualmente é vice-presidente do Consel ho de A dministração do Unibanco, que tem presença constante no ranking das maiores instituições financeiras do país nos últimos anos. A lém de fazer parte da diretoria da Febraban, foi também vice-presidente da Confederação $\mathrm{N}$ acional das Instituições Financeiras (CNF), nas duas últimas gestões.

Em seu discurso de posse, ${ }^{20}$ Ferreira chamou a atenção por ser a primeira vez que a entidade seria presidida por um advogado, e não propriamente por um empresário do sistema financeiro. $M$ anifestou, ainda, seu profundo agradecimento ao governo FHC por ter dado apoio decisivo ao conjunto de reformas legislativas e constitucionais que favoreceram as instituições financeiras nos últimos anos, ressal tando, dentre outras, a L ei de R esponsabilidade Fiscal. Salientou ainda a necessidade do governo e das instituições financeiras combinarem esforços e recursos, com o intuito de mel horar seu entrosamento. Entre outras medidas, no que se refere à Febraban, destacou a concorrência livre e

19. Fonte: Revista Exame: Melhores e Maiores - as 500 maiores empresas do Brasil. A nos 1998-2001.

20. A posse da atual diretoria da Febraban/Fenaban ocorreu no dia 12 de março de 2001 no Clube Monte Líbano, em São Paulo. Disponível em: <http://www.febraban.org.br/ item7.asp>. A cesso em: 23 out. 2002 
MIRANDA, ELflay. Globalização financeira e associações de bancos no Brasil:...

Quadro 1 - Diretoria da Febraban no período de 1998-2001*

\begin{tabular}{|c|c|c|c|c|c|c|c|}
\hline \multicolumn{8}{|c|}{ Vínculos dos diretores da Febraban no período 1998-2001 } \\
\hline Diretoria 1998-2001 & $\begin{array}{l}\text { Bancos/Grupos } \\
\text { financeiros }\end{array}$ & $\begin{array}{l}\text { Origem } \\
\text { capital }\end{array}$ & Estatais & $\begin{array}{l}\text { Assoc. setor } \\
\text { financeiro }\end{array}$ & $\begin{array}{l}\text { Outras assoc. } \\
\text { empres ariais }\end{array}$ & $\begin{array}{l}\text { Inst. } \\
\text { fund. }\end{array}$ & $\begin{array}{l}\text { Outras } \\
\text { assoc. }\end{array}$ \\
\hline $\begin{array}{l}\text { Roberto Egydio Setúbal } \\
\text { Presidente }\end{array}$ & Banco Itaú & Brasil & Petrobrás(1) & Fenaseg & $\begin{array}{l}\text { Ceal } \\
\text { Amcham }\end{array}$ & FibCT & ASFL \\
\hline $\begin{array}{l}\text { Paulo Lobato Ribeiro } \\
\text { Vice-presidente }\end{array}$ & Banco Real & Holanda & & FGC & & & Abccmm \\
\hline $\begin{array}{l}\text { Gabriel Jorge Ferreira } \\
\text { Vice-presidente }\end{array}$ & Unibanco & Brasil & & $\begin{array}{l}\text { CNF } \\
\text { Abecip }\end{array}$ & ISE & AVCIMS & \\
\hline \begin{tabular}{|l|} 
Ageo Silva \\
Diretor \\
\end{tabular} & Bradesco & Brasil & & Cetip & & & IE \\
\hline $\begin{array}{l}\text { Antonio Beltran Matinez } \\
\text { Diretor }\end{array}$ & \begin{tabular}{|l} 
BBA \\
Creditanstalt
\end{tabular} & Brasil & & Abbc & & & $\begin{array}{l}\text { Apcd } \\
\text { Abccmm }\end{array}$ \\
\hline $\begin{array}{l}\text { Antonio Carlos Castrucci } \\
\text { Diretor }\end{array}$ & Banco Paulista & Brasil & & Abbc & $\begin{array}{l}\text { Sebrae } \\
\text { FCE }\end{array}$ & & ARC \\
\hline $\begin{array}{l}\text { Bernard Paul Mencier } \\
\text { Diretor }\end{array}$ & $\begin{array}{l}\text { Banco CCF } \\
\text { Brasil ** }\end{array}$ & Inglaterra & & & Amcham & & \\
\hline $\begin{array}{l}\text { Carlos Alberto Vieira } \\
\text { Diretor }\end{array}$ & Banco Safra & Brasil & & & Ccba & & \\
\hline $\begin{array}{l}\text { Hélio Ribeiro Duarte } \\
\text { Diretor }\end{array}$ & HSBC & Inglaterra & & $\begin{array}{l}\text { Abbi } \\
\text { Abecip }\end{array}$ & Ibef & FGV & \\
\hline $\begin{array}{l}\text { Hugo Dantas Pereira } \\
\text { Diretor }\end{array}$ & Banco do Brasil & Brasil & ICPAntaq & & & & Abace \\
\hline $\begin{array}{l}\text { Murillo Carvalho Jr. } \\
\text { Diretor }\end{array}$ & $\begin{array}{l}\text { Fleming } \\
\text { Graphus*** }\end{array}$ & EUA & & Bvrj & Amcham & & FAF \\
\hline $\begin{array}{l}\text { Raul Pereira Barreto } \\
\text { Diretor }\end{array}$ & Mercantil-Finasa & Brasil & & FGC & & & \\
\hline
\end{tabular}

Fonte: Febraban/Secretaria Geral da Presidência em 19 dez. 2002.

Quadro elaborado pelo autor.

(1) Participou do Conselho da Empresa.

* A composição da direção da entidade sofreu mudanças durante a sua gestão.

**O Banco CCF Brasil é subsidiária do Crédit Commercial de France, que pertence desde 2000 ao HSBC Investment.

*** Banco Fleming Graphus S.A., adquirido em julho de 2000, pelo Chase Manhattan Bank do Grupo J.P. Morgan.

Legenda:

A bace - A ssociação Brasiliense de A posentados do Banco Central $A B B C$ - A ssociação Brasileira de Bancos Comerciais e Múltiplos $A B B I$ - A ssociação Brasileira de $B$ ancos Internacionais

A B CCM M - A ssociação B rasileira de Criadores do Cavalo M angalarga

A becip - A ssociação B rasileira das Entidades de Crédito Imobiliário e Poupança

A M CHAM - Câmara A mericana de Comércio

A ntaq - A gência Nacional de Transportes A quaviários

$A P C D$ - Associação de Parceria contra D rogas

A RC - A Ifa Romeu Clube

AS - A méricas Society Organization

AV C - A ssociação Viva o Centro

BVRJ - Bolsa de Valores do Rio de Janeiro

CCBA - Câmara de Comércio B rasileira A mericana

CEA L - Consel ho de Empresários da A mérica L atina

Cetip - Central de Custódia e Liquidação
CNF - Confederação Nacional das Instituições Financeiras CT - Comissão Trilateral

FA F - Fundação A ry Frauzino para Pesquisa e Controle do Câncer

FCE - Empresa de Consultoria Financeira

Fenaseg - Federação Nacional das Empresas de Seguros Privados e Capitalização

FGC - Fundo Garantidor de Créditos

FGV - Fundação G etúlio Vargas

FIB - Fundação I taubanco

FL - Fórum de Líderes

Ibef - Instituto Brasileiro de Executivos de Finanças de São Paulo

ICP - B rasil - Infra-Estrutura de Chaves Públicas Brasileira

IE - Pastor de Igreja Evangélica

IMS - Instituto M oreira Salles

ISE - Instituto Superior da Empresa

Sebrae - Serviço Brasileiro de A poio às M icro e Pequenas Empresas efetiva de instituições bancárias brasileiras e estrangeiras, públicas e privadas, grandes, médias ou pequenas, que, segundo ele, impulsionariam a melhoria da qualidade e redução dos custos do sistema bancário no Brasil.

Em uma análise dos mercados financeiro nacional e internacional, ${ }^{21}$ Ferreira alertou que

21. Depoimento de Gabriel Jorge Ferreira à revista $F$ ortune, em 3 abr. 2001. os três maiores bancos nacionais (B radesco, I taú e U nibanco) possuíam, em dezembro de 1995, o volume de $25 \%$ do total de depósitos à vista, enquanto os bancos estrangeiros (HSBC, B oston, Citibank, B BV, A B N A mro e Santander) detinham 7,5\%. Em dezembro de 2000, os três maiores bancos nacionais haviam expandido sua participação nos depósitos à vista para 29\% e os estrangeiros para 16\%. Com relação ao volume de crédito, a situação era semelhante. 
A participação dos três maiores bancos privados no total de operações de crédito saltou de $13 \%$ para $21 \%$ entre dezembro de 1995 e 2000 , enquanto a dos bancos estrangeiros aumentou de $7,8 \%$ para $13,8 \%$, ou seja, tanto a participação dos maiores bancos privados brasileiros quanto dos bancos estrangeiros aumentaram nesse período, o que, para Ferreira, é um reflexo do processo de consolidação do sistema bancário e da redução da participação do sistema bancário estatal, como já vimos anteriormente. Sobre isso, Ferreira destaca que a eficiência do sistema bancário brasileiro provém da competição tanto entre bancos privados nacionais quanto entre nacionais e estrangeiros.

Sobre a Contribuição Provisória Sobre M ovimentação Financeira (CPM F), 22 o presidente da Febraban afirmou que uma alíquota de $0,38 \%$ é muito alta sobre as transações financeiras, mas, por outro lado, a arrecadação da CPM F em 2001 foi superior a R $\$ 16$ bilhões, 0 que foi fundamental no equilíbrio das contas públicas. M esmo assim, 0 atual governo precisa atingir a meta de $4,25 \%$ do Produto Interno B ruto (PIB) para um superávit primário, ou seja, $0,37 \%$ a mais que no ano passado, que foi de $3,88 \%$ do PIB. ${ }^{23}$

Ferreira manifestou, ainda, elogios à política de desestatização implementada nos últimos anos pelo governo de FHC, em que o Bacen, segundo ele, "tem feito um importante trabal ho de mel horia da regulamentação e supervisão do sistema bancário". Ressal tou também que, até 2005, "a concorrência se manterá el evada, com bancos privados de capital nacional e estrangeiro dividindo o mercado e certamente com uma menor presença do sistema bancário estatal". Para Ferreira, a eficiência da intermediação financeira torna "os recursos mais baratos para o tomador e a remuneração do poupador será melhor". ${ }^{24}$

22. 0 imposto sobre movimentação financeira foi implantado no Brasil como IPM F e, posteriormente, transformado em CPM F. É basicamente um tributo sobre transações financeiras, com uma alíquota incidente sobre o valor de cada movimentação de débito - não só de cheques - em conta corrente de clientes bancários. Portanto, é pago por quem tem conta em banco e movimenta recursos pelo banco.

23. Folha de São Paulo, 11 fev. 2003.

24. Discurso de Gabriel Jorge Ferreira, sobre a posição da entidade, no seminário "O A primoramento e o Fortalecimento do Sistema Financeiro Nacional", em 23 out. 2002.
Em um dos posicionamentos da entidade, 0 presidente da Febraban reafirmou 0 apoio do sistema financeiro nacional à criação do Conselho de Desenvolvimento Econômico e Social (CDES).

0 CDES tem a metade dos seus 82 integrantes composta por grandes empresários, dentre eles B enjamin Steinbruch (Companhia Siderúrgica N acional) e J orge Gerdau (G rupo Gerdau e ex-diretor do Instituto Liberal). Do setor financeiro, são originários sete consel heiros, representando grandes instituições como A B N A mro B ank, Citibank, B radesco, Santander, I taú e a própria Febraban. Participam também do CDES o Sindicato dos B ancários de São Paulo e outras instituições de grande porte..$^{25}$

Gabriel J orge F erreira lembrou que o setor está disposto a contribuir em várias frentes, principalmente em relação ao crédito, o que será fundamental para promover o desenvolvimento almejado pelo novo governo. Segundo Ferreira, "o crédito no B rasil sofre distorções, mas quando forem corrigidas, deve contribuir para diminuir rapidamente o custo do dinheiro". ${ }^{26} \mathrm{Em}$ atenção à solicitação contida no convite para participar da reunião sobre a definição de uma agenda para - CDES, a Febraban sugere que el e seja constituído por entidades da sociedade civil organizada, ou seja, de instituições setoriais e de classe como ONGs, representações sindicais, além de notáveis.

Sobre a campanha presidencial, em seus boletins e meios de divulgação, a entidade pouco se manifestou sobre o assunto, mas em reuniões com a equipe do então candidato a presidência Luiz Inácio Lula da Silva (PT) a Febraban mostrou-se disposta a colaborar com um novo governo. Em uma de suas entrevistas, Gabriel J orge Ferreira, comentou: "a apresentação feita pelo candidato nos surpreendeu [diretoria da Febraban] de forma muito favorável. Foi um discurso franco, construtivo e com al to grau de desprendimento" ${ }^{27} \mathrm{Na}$ mesma reunião, Lula

\footnotetext{
25. Folha de São Paulo, 6 fev. 2003.

26. Relatório da Superintendência de Comunicação Social da Febraban.

27. Entrevista realizada com o presidente da Febraban, após uma reunião com o então candidato à presidência da República, Lula da Silva, e sua equipe econômica em 20 de agosto de 2002, na sede da entidade. Fonte: www.programalula. com.br/noticias/noticias_int.asp?cod=168.
} 
destacou que a sua principal preocupação, no caso do sistema financeiro, era a de torná-lo de fato uma alavanca para o desenvolvimento do setor produtivo. Segundo Lula, sua intenção seria montar um grupo de trabal ho conjunto entre sua equipe econômica e a da Febraban. Seria o terceiro grupo de trabalho que Lula teria organizado. 0 primeiro foi com empresários da A ssociação B rasileira da Indústria de Base $(A B \mid B)$, e 0 outro com a A ssociação de Institutos Estaduais de Pesquisa A gropecuária.
No Quadro 2, temos a relação da diretoria da Febraban, com importantes segmentos da sociedade, como vimos no item anterior. Podemos observar que cerca de $41 \%$ de cargos da diretoria da entidade pertencem a bancos estrangeiros, sendo três europeus e dois americanos. Os dois maiores bancos americanos operantes no mercado brasileiro fazem parte da diretoria da entidade. O utro fator interessante é que $75 \%$ da diretoria é representada pelos maiores bancos do país nos últimos anos. ${ }^{28}$ Os maiores bancos

Quadro 2 - Diretoria da Febraban no período de 2001-2003*

\begin{tabular}{|c|c|c|c|c|c|c|c|}
\hline \multicolumn{8}{|c|}{ Vínculos dos diretores da Febraban no período 2001-2003 } \\
\hline Diretoria 2001-2003 & $\begin{array}{l}\text { Bancos/Grupos } \\
\text { financeiros }\end{array}$ & $\begin{array}{l}\text { Origem } \\
\text { capital }\end{array}$ & Estatais & $\begin{array}{l}\text { Assoc. setor } \\
\text { financeiro }\end{array}$ & $\begin{array}{l}\text { Outras } \\
\text { associações } \\
\text { empresariais }\end{array}$ & $\begin{array}{l}\text { Inst. } \\
\text { fund. }\end{array}$ & $\begin{array}{l}\text { Outras } \\
\text { associações }\end{array}$ \\
\hline $\begin{array}{l}\text { Gabriel Jorge Ferreira } \\
\text { Presidente }\end{array}$ & Unibanco & Brasil & & $\begin{array}{l}\text { CNF } \\
\text { Abecip }\end{array}$ & ISE & $\begin{array}{l}\text { AVC } \\
\text { IMS }\end{array}$ & Cdes** \\
\hline $\begin{array}{l}\text { Fábio Colletti Barbosa } \\
\text { Vice-presidente }\end{array}$ & ABN Amro Real & Holanda & & $\begin{array}{l}\text { Abbi } \\
\text { FGC }\end{array}$ & & & Cdes \\
\hline $\begin{array}{l}\text { Antonio Carlos Castrucci } \\
\text { Diretor }\end{array}$ & Banco Paulista & Brasil & & Abbc & $\begin{array}{l}\text { Sebrae } \\
\text { FCE }\end{array}$ & & ARC \\
\hline $\begin{array}{l}\text { Antonio Jacinto Matias } \\
\text { Diretor }\end{array}$ & Banco Itaú & Brasil & & & & & \\
\hline $\begin{array}{l}\text { Carlos Alberto Vieira } \\
\text { Diretor }\end{array}$ & Safra & Brasil & & Ccba & & & \\
\hline $\begin{array}{l}\text { Décio Tenerello } \\
\text { Diretor }\end{array}$ & Bradesco & Brasil & & Abecip & Cibrasec & & Fiabci \\
\hline $\begin{array}{l}\text { Geraldo José Carbone } \\
\text { Diretor }\end{array}$ & Bank Boston & EUA & & & & & \\
\hline $\begin{array}{l}\text { Gustavo Marin Garat } \\
\text { Diretor }\end{array}$ & Citibank & EUA & & Amcham & & & Cdes \\
\hline $\begin{array}{l}\text { Hélio Ribeiro Duarte } \\
\text { Diretor }\end{array}$ & HSBC & Inglaterra & & $\begin{array}{l}\text { Abbi } \\
\text { Abecip }\end{array}$ & Ibef & FGV & \\
\hline $\begin{array}{l}\text { Jorge Luiz Ávila da Silva } \\
\text { Diretor }\end{array}$ & $\begin{array}{l}\text { Caixa } \\
\text { Econômica } \\
\text { Federal }\end{array}$ & Brasil & Eletrobrás & $\begin{array}{l}\text { Andima } \\
\text { Asbace }\end{array}$ & Ibef & $\begin{array}{l}\text { FGV } \\
\text { Ibmec }\end{array}$ & Fenae \\
\hline $\begin{array}{l}\text { Miguel Jorge Filho } \\
\text { Diretor }\end{array}$ & $\begin{array}{l}\text { Santander } \\
\text { Banespa }\end{array}$ & Espanha & & & & & Cdes \\
\hline $\begin{array}{l}\text { Hugo Dantas Pereira } \\
\text { Diretor }\end{array}$ & Banco do Brasil & Brasil & $\begin{array}{l}\text { ICP } \\
\text { Antaq }\end{array}$ & & & & Abace \\
\hline
\end{tabular}

Fonte: Febraban em 10 fev. 2003

Quadro elaborado pelo autor.

* A composição da diretoria sofreu mudanças durante a gestão que ainda não se encerrou.

***articipa representando a Febraban, e não o Unibanco.

L egenda:

A bace - Associação B rasiliense de A posentados do B anco Central

$A B B C$ - A ssociação Brasileira de Bancos Comerciais e M últiplos

$A B B I$ - A ssociação Brasileira de Bancos Internacionais

A becip - A ssociação B rasileira das Entidades de Crédito Imobiliário e

Poupança

A M CHAM - Câmara A mericana de Comércio

A ndima - A ssociação $\mathrm{N}$ acional das Distribuidoras de $\mathrm{M}$ ercado $\mathrm{A}$ berto

A ntaq - A gência Nacional de Transportes A quaviários

ARC - Alfa Romeu Clube

A sbace - A ssociação Brasileira de B ancos Estaduais

AV C - A ssociação Viva o Centro

CCBA - Câmara Brasileira de Comércio A mericana

CDES - Conselho de Desenvolvimento Econômico e Social

Cibrasec - Companhia B rasileira de Securitização

CNF - Confederação Nacional das Instituições Financeiras
FENAE - Federação Nacional das A ssociações de Pessoal da Caixa FCE - Consultoria Financeira

FGC - Fundo Garantidor de Créditos

FGV - Fundação G etúlio Vargas

$\mathrm{FIABCl}$ - Federação Internacional das Profissões Imobiliárias

IBEF - Instituto Brasileiro de Executivos de Finanças de São Paulo

ICP - Infra-Estrutura de Chaves Públicas B rasileira

IMS - Instituto M oreira Salles

ISE - Instituto Superior da Empresa

28. Fonte: Revista Exame: Melhores e Maiores - as 500 maiores empresas do Brasil. A nos 1998-2001. 
estatais do país (Caixa E conômica Federal e o $B$ anco do B rasil) também estão representados. Há ainda três diretores da entidade ligados ao CDES.

A nálise comparativa entre as gestões 1998-2001 e 2001-2003

A pesar de a última gestão da diretoria da Febraban ainda não ter se encerrado, temos indicadores que nos remetem a algumas conclusões. A o observarmos os Q uadros 1 e 2 , podemos ver que $50 \%$ da diretoria nas duas gestões foi ocupada pelos mesmos bancos. Desse total, $66 \%$ da diretoria é representada pelas maiores instituições bancárias do país.

0 capital estrangeiro tem uma crescente representação na entidade. De quatro bancos em 2001, a entidade passou a ter cinco bancos de capital estrangeiro em sua diretoria, sendo que o capital europeu é maior em relação ao norte-americano.

0 capital estatal também se faz presente e com uma representatividade maior em 2001. A lém do B anco do Brasil, a Caixa também passou a fazer parte da diretoria da Febraban.

A baixa rotatividade na diretoria e a forte presença do capital estrangeiro permitem concluir que a diretoria da Febraban, nessas duas últimas gestões, acompanha a tendência do Sistema Financeiro Latino-americano, em que poucas e fortes instituições financeiras controlam ou hegemonizam as diretorias de suas representações de classe, tendo assim mais força na defesa de seus interesses e maior poder de pressão sobre decisões do aparato estatal.

\section{A Febraban e o artigo 192 da Constituição}

Pelo artigo 192 da Constituição Federal, que dispõe sobre o funcionamento do Sistema Financeiro $\mathrm{Nacional}$, mas ainda não foi regulamentado, ${ }^{29}$ todos os aspectos do sistema financeiro terão de ser regulamentados por uma única lei complementar. Val e destacar que desde 1988 os parlamentares tentam produzir um projeto que contemple todos os aspectos e que

29. A análise da relação entre a Febraban e 0 artigo 192 vai até o final da pesquisa, ou seja, dezembro de 2002. Desde então, eventuais mudanças não foram analisadas pelo autor. conte com o apoio da maioria absoluta no Congresso.

0 artigo citado determina que o Sistema Financeiro será regulado por lei complementar, que disporá, basicamente, entre outras coisas sobre:

a) a autorização de funcionamento de instituições financeiras, estabelecimentos de seguro, previdência e capital ização e respectivos órgãos da fiscalização;

b) participação de capital estrangeiro nas instituições;

c) organização, funcionamento e atribuições do Banco Central;

d) fundo de seguro para a economia popular; crédito

e) funcionamento das cooperativas de

f) limitação das taxas de juros reais a $12 \%$.

A Febraban, com seu poder de pressão perante o Congresso, sempre manteve influência nas decisões que regem a legislação sobre o sistema financeiro brasileiro. Como já citado anteriormente, uma comissão importante que ocupa a diretoria da Febraban reserva-se às discussões sobre a legislação que disciplina as atividades do sistema financeiro no país, ou seja, 0 artigo 192.

Em função da relevância para a economia nacional, o artigo 192 sempre foi alvo de freqüentes e intensos debates no Congresso $N$ acional, em que já existiram projetos de revisão do próprio artigo e de sua disciplina por meio de lei complementar, como a Proposta de E menda Constitucional (PEC) no 53, de 1999, que foi apresentada ao Congresso $\mathrm{N}$ acional pelo Senador J osé Serra (PSD B -SP). Tal proposta desregulamenta 0 artigo, "ao eliminar todos os incisos referentes às matérias que deveriam ser regulamentadas por lei única - do limite máximo de $12 \%$ de juros ao ano, que nunca passou de letra morta, ao funcionamento do Banco Central". 30

A PEC do então senador Serra foi relatada pelo senador J efferson Peres (PDT-AM), que apresentou um substitutivo. Nele, o senador

30. Revista Por Sinal, ago. 2001. 
Peres determinou que a regulamentação fosse feita por leis complementares e retirou o dispositivo da Constituição que limita a taxa de juros reais em $12 \%$. U ma parte significativa do Partido dos Trabal hadores nunca acei tou essa supressão e por causa disso, principalmente, a PEC não chegou a ser votada pelo plenário da Câmara. ${ }^{31}$ 0 texto da PEC para o artigo 192 já aprovado no Senado é o seguinte:

O Sistema Financeiro $\mathrm{N}$ acional, estruturado de forma a promover o desenvolvimento equilibrado do País e a servir aos interesses da coletividade, em todas as partes que o compõe, abrangendo as cooperativas de crédito, será regulado por leis complementares, que disporão, inclusive, sobre a participação do capital estrangeiro nas instituições que o integram.

No âmbito do Congresso Nacional, funciona desde 1991, na Câmara dos D eputados, uma Comissão Especial do Sistema Financeiro, com a finalidade de discutir projetos destinados à disciplina do artigo 192, cujos importantes depoimentos foram colhidos sobre o tema com os mais representativos segmentos do empresariado financeiro no país, entre eles o de A ntônio B ornia, presidente da Confederação Nacional das Instituições Financeiras ${ }^{32}$ (CNF), J oão Elísio Ferraz Campos, presidente da Federação $\mathrm{N}$ acional das E mpresas de Seguros Privados e Capitalização (Fenaseg), e de Gabriel Jorge Ferreira, presidente da Febraban.

A Febraban tem participado das discussões relativas ao artigo 192 e seus presidentes sempre se fizeram presentes nas discussões sobre 0 tema. No depoimento de Ferreira à Comissão Especial que trata do assunto, entre outros temas, o que mais chamou a atenção foi o relativo à prática da taxa de juros. Segundo a Febraban,

hoje há quase um consenso em que limitar os juros em $12 \%$ é absolutamente inviável. 0 dinheiro, como qualquer mercadoria, é regido por leis de mercado. Portanto, não há como se

31. Valor Econômico, 19 fev. 2003.

32. É um órgão de grau superior do empresariado, que congrega entidades de classe de âmbito nacional, as quais representam os diversos segmentos do empresariado financeiro no Brasil. falar em tabelamento de juros, muito menos na Constituição Federal. ${ }^{33}$

Para a Febraban, o sistema financeiro é apenas um intermediário que está situado entre duas pontas: o titular dos recursos, o poupador; e aquele que toma emprestado, o tomador. Portanto, a regulamentação da intermediação financeira é fundamental para que ela seja eficiente e não onerosa. Para a entidade, ainda, a regulamentação do sistema financeiro deveria ter como objetivo um custo de capital final o mais baixo possível. A preocupação do legislador deveria ser 0 de criar condições para um juro básico baixo e intermediação financeira eficiente.

Em outro posicionamento da Febraban quanto a uma possível lei que vier regulamentar o Sistema Financeiro, como de resto também outros mercados, esta teria de prever a existência de comissões temáticas, consultivas, em que segmentos da sociedade estivessem representados, ou seja, o processo normativo do sistema financeiro deveria, de certa forma, guardar uma certa equivalência com o que acontece no Congresso Nacional, em que existem as Comissões, as relatorias, os depoimentos, e efetiva publicidade das discussões e das emendas.

Quanto à entrada de capital estrangeiro no país, a Febraban, por meio de seu presidente, ressalta que "os exemplos recentes dos bancos privatizados e o interesse pel o $B$ rasil como local ideal para se investir mostra claramente que a visão estratégica desses grandes bancos é de que o país é, sem dúvida, o grande alvo da A mérica L atina".

Em seu discurso de posse, ${ }^{34} 0$ atual presidente da Febraban relata que uma meta importante em seu trabalho diante da disposição do artigo 192 seria o de apoiar a PEC, mediante algumas modificações, dentre elas: instalar 0 funcionamento das comissões consultivas, que institui o Plano Real, tornando a estrutura

33. Posicionamento da CNF, da Febraban e da Fenaseg acerca da PEC no 53, de 1999, relativa ao SFN. Câmara dos Deputados, Departamento de Taquigrafia, doc. o 000606/ 01 de 21 jun. 2001, $53 \mathrm{p}$.

34. Disponível em: <http://www.febraban.org.br/item7.asp.> A cesso em: 23 out. 2002. 
normativa do Sistema Financeira Nacional mais participativa, ou seja, a entidade com mais poder de participação nas decisões do sistema financeiro nacional; criação de mecanismos de defesa da poupança pública, em parceria com o governo federal, para absorver as funções do Fundo Garantidor de Créditos.

Para a Febraban, é de grande interesse a aprovação da PEC, pois cada segmento do mercado financei ro seria regulamentado por lei própria. A ssim, entidades representativas de classe, como a Febraban, poderiam facilmente utilizar-se de lobbies no Congresso, para resguardar seus interesses.

Outra grande preocupação da Febraban é com a recuperação de créditos. Para a entidade, quanto maior o direito dos bancos em executar e recuperar uma dívida, menor será seu prejuízo. A entidade baseia-se no exemplo dos Estados Unidos, onde a facilidade de um credor de financiamento hipotecário em recuperar o imóvel em garantia é tão grande, que o mercado opera com margens inferiores a $2 \%$ ao ano. Isso atinge diretamente a população, que com dívidas contraídas por altas taxas de juros, financiamentos e cheques especiais não pode quitar seus empréstimos, tendo assim de executar seus bens para quitar as dívidas.

$\mathrm{Na}$ A mérica L atina, não só o Brasil sofre os problemas com a desregulamentação do Sistema Financeiro Nacional. Países como a A rgentina, Chile e M éxico também estão modificando suas legislações a fim de tornar mais fácil a entrada de capital estrangeiro em seus países. Isso parece mostrar a perversa tendência seguida pelos países latino-americanos pressionados por entidades de classe com poder baseados no dinheiro, ou seja, o empresariado financeiro, seguindo assim os padrões e normas estabelecidas, pelo novo modo de acumulação capitalista.

\footnotetext{
Abstract: The present article makes an analysis trough a social and political vision the structure and the dynamics of one of the most important agencies in Brazil representing the financial Brazilian market: the Febraban (Federação Brasileira de Bancos) between a period from 1998 through 2001 and 2001 through 2003. It has been analyzed board relationship with other organizations and
}

its politics related with political-economic scenery mainly the 192 article of the Brazilian Constitution that deals with national financial system.

K ey-words: financial entrepreneur; financial system; Febraban; banks.

\section{Referências}

ARAÚJ0, Ângela C; TA PIA, Jorge B. Corporativismo e neocorporativismo: regime de duas trajetórias. BIB, Rio de Janeiro, n. 32, p. 3-30, 20 semestre de 1992.

BOSCHI, Renato R. Elites industriais e democracia. Rio deJ aneiro: Graal, 1979.

BOSCHI, Renato R; DINIZ, Eli; SANTOS, Fabiano. Elites políticas e econômicas no Brasil contemporâneo: a desconstrução da ordem corporativa e o papel do L egislativo no cenário pós-reformas. São Paulo: Fundação K onrad A denauer, 2000. 117 p. (Série Pesquisas no 18).

BRA GA, J osé Carlos de Souza. Financeirização gl obal: o padrão sistêmico de riqueza do capitalismo contemporâneo. In: TAVA RES, M aria da Conceição; FIORI, José Luís (Orgs.). Poder e dinheiro: uma economia política da gl obalização. 2. ed. Petrópolis: Vozes, 1997. p. 195-242.

BRA SIL . Constituição da República F ederativa do Brasil. B rasília: Senado Federal, Centro Gráfico, 1988. $292 \mathrm{p}$.

CHESNA IS, François. A emergência de um regime de acumulação mundial predominantemente financeiro. Praga - Revista de Estudos Marxistas, n. 3, São Paulo: Hucitec, p.19-46, 1997.

COLEMAN, William D. Policy convergence in banking: a comparative study. Political studies, $v$. XLII, p. 274-292, 1994.

COSTA , Paulo R. N eves da. De volta à questão da burguesia brasileira. Revista de Sociologia e Política, Curitiba, n.14, p. 201-204, jun. 2000.

DINIZ, Eli. Empresário, Estado e capitalismo no Brasil: 1930-1945. Rio de J aneiro: Paz eTerra, 1978. 311 p. (Coleção Estudos B rasileiros, v. 27).

DINIZ, Eli. G lobalização, reformas econômicas e elites empresariais: B rasil anos 90. Rio de J aneiro: Ed. FGV, 2000.

DREIFUSS, Renné. A internacional capitalista: estratégias e táticas do empresariado transnacional 1918-1986. Rio de J aneiro: Editora Espaço e Tempo, 1986.

FITOUSSI, Jean-Paul. 0 debate-tabu. M oeda, Europa, pobreza. Lisboa: Terramar, 1997. 
FREITAS, M aria C. Penido de; PRATES, D aniela M . $A$ bertura financeira na $A$ mérica $L$ atina: as experiências da Argentina, Brasil e M éxico. Economia e Sociedade, n. 11, Campinas, p 173-198, dez. 1998.

JINK INGS, Nise. Trabalho e resistência na "fonte misteriosa" : os bancários no mundo da el etrônica e do dinheiro. Campinas, SP: Editora da U nicamp; São Paulo: Imprensa Oficial do Estado, 2002.

LEOPOLDI, M ariaA ntonieta P. Política e interesses na industrialização brasileira: as associações industriais, a política econômica e o Estado. São Paulo: Paz eTerra, 2000.

MICK, Jacques. A globalização financeira e as mudanças na regulação do sistema financeiro nacional (1194-1196): um estudo sobre a hegemonia financeira. Florianópolis, 1998. Dissertação (M estrado) - PPGSP, UFSC, Florianópolis, 1998.

M INELLA , A ry C. Banqueiros: organização e poder político no B rasil. Rio de Janeiro: E ditora Espaço e Tempo, A npocs, 1988. $530 \mathrm{p}$.

. Globalização financeira e as associações de bancos na A mérica Latina. In: SEM INÁ RIO TEM Á TICO: PARA ONDE VAI O CAPITALISMO NO BRASIL? DILEMASE PERSPECTIVAS DASEM PRESASE DOSEM PRESÁRIOS, 2001, Caxambu, M G. Anais... Caxambu, M G, 2001.

MIRANDA, José Carlos; TAVARES, Maria da Conceição. B rasil: estratégias de conglomeração. In: FIORI, J osé Luís (Org.). Estados e moedas no desenvolvimento das nações. 3. ed. Petrópolis, R.J: Vozes, 2002. p. 327-350.

ROCHA, Fernando A lberto $S$. Desnacionalização bancária no Brasil (1997-2000). Campinas, SP, 2002. Dissertação (M estrado) - IE: U nicamp, Campinas, SP, 2002.

WA LLER STEIN , I mmanuel. A reestruturação capitalista e o sistema-mundo. IN : GENTIL LI, Pablo
(Org.). Globalização excludente: desigualdade, exclusão e democracia na nova ordem mundial. Petrópolis, RJ: Vozes; Buenos A ires; Clacso, 2000. p. 223-251 (Coleção A Outra M argem).

Sites

A ssociação B rasileira de B ancos Internacionais. www.abbi.com.br. Último acesso em: 6 nov. 2002.

B anco Central do B rasil - www.bc.gov.br. Último acesso em: 7 nov. 2002.

Câmara dos D eputados - www.camara.gov.br. Último acesso em: 6 nov. 2002.

Comissão deVal ores M obiliários - www.cvm.gov.br. Último acesso em: 25 out. 2002.

Confederação $\mathrm{N}$ acional das Instituições Financei ras - www.cnf.com.br. Último acesso em: 9 nov. 2002.

Federação B rasileira das A ssociações de B ancos www.febraban.org.br. Último acesso em: 8 nov. 2002.

Revista dos Funcionários Banco Central - www. porsinal .org.br. Último acesso em: 8 nov. 2002.

Senado Federal - www.senado.gov.br. Último acesso em: 6 nov. 2002.

Sites de jornais:

Diário Catarinense - www.clicrbs.com.br. Último acesso em: 8 nov. 2002.

Estado de São Paulo - www.estadao.com.br. Último acesso em: 8 nov. 2002.

Folha de São Paulo - www.folha.com.br. Último acesso em: 8 nov. 2002.

Gazeta M ercantil - www.gazeta.com.br. Último acesso em: 8 nov. 2002.

Valor E conômico - www.valor.com.br. Último acesso em: 8 nov. 2002. 